\title{
Second permanent molars: embryological origin, development and eruption. Role of the RANK/RANKL/OPG pathway
}

\author{
B. Castaneda $1,2,3$, F. Lezot ${ }^{4}$ \\ 1 Dentofacial Orthopedics Department, Pitié-Salpêtrière Hospital, Paris, France \\ 2 Molecular oral pathophysiology laboratory, INSERM UMR 1138, Paris, France \\ 3 Faculty of Odontologie, Antioquia University, Colombia \\ ${ }_{4}^{4}$ INSERM UMR 957, University of Nantes, France
}

\begin{abstract}
Craniofacial skeleton formation, and more specifically alveolar bone development, follow a finely regulated controlled genetic program. A spatial and temporal combination of molecular signals determines the type and inter- and intra-maxillary position of each dental-alveolar unit. The volumetric growth and movement of tooth germs depend on a coordinated adaptive peripheral alveolar bone modeling process which is supported by signaling pathways between cells of the dental epithelium, dental follicle and alveolar bone. These signaling pathways involve transcription factors, proto-oncogenes and diffusible factors called "growth factors." Transient impairment of these signals during time windows corresponding to the development of the various dental types could explain specific localized eruption deficits in a given dental type, as observed for second molars. Ongoing studies show that disturbances of bone resorption related to disruption of the RANKL/RANK/OPG signaling pathway affect tooth eruption and root morphogenesis, with a clear relationship between the time window of onset of disruption and the affected dental type.
\end{abstract}

KEYWORDS

Odontogenesis, tooth eruption, RANKL/RANK/OPG signaling pathway, PTH-rP

\section{EMBRYOLOGICAL ORIGIN AND DEVELOPMENT OF PERMANENT SECOND MOLARS}

The craniofacial skeleton derives from neural crest cells (NCCs), a population of pluripotent cells emerging from the central nervous system (dorsal aspect of neural tube) and following various migration pathways depending on the site of origin: cephalic, vagal, truncal or lumbosacral ${ }^{3}$. The facial skeleton derives from cephalic NCCs. These neuroectodermal cells, originating from the boundary between the
Address for correspondence:

Beatriz Castaneda - Facultad de Odontologia,

Universidad de Antioquia - Colombia

Laboratoire de Physiopathologie

Orale Moléculaire, INSERM 1138

15 Rue de l'École de Médecine,

75270 Paris 06, France

E-mail: bea.castaneda.1@gmail.com
Article received: 03-05-2015. Accepted for publication: 30-05-2015.

This is an Open Access article distributed under the terms of the Creative Commons Attribution License (http://creativecommons.org/licenses/by/4.0), which permits unrestricted use, distribution, and reproduction in any medium, provided the original work is properly cited. 
neural and non-neural ectoderms (dorsal aspect of neural tube), undergo epithelial-mesenchymal transformation, required for migration ${ }^{32}$.
Once at their final destination, they proliferate to form the facial structures via 5 branchial or pharyngeal arches (fig. 1A). These mesenchymal

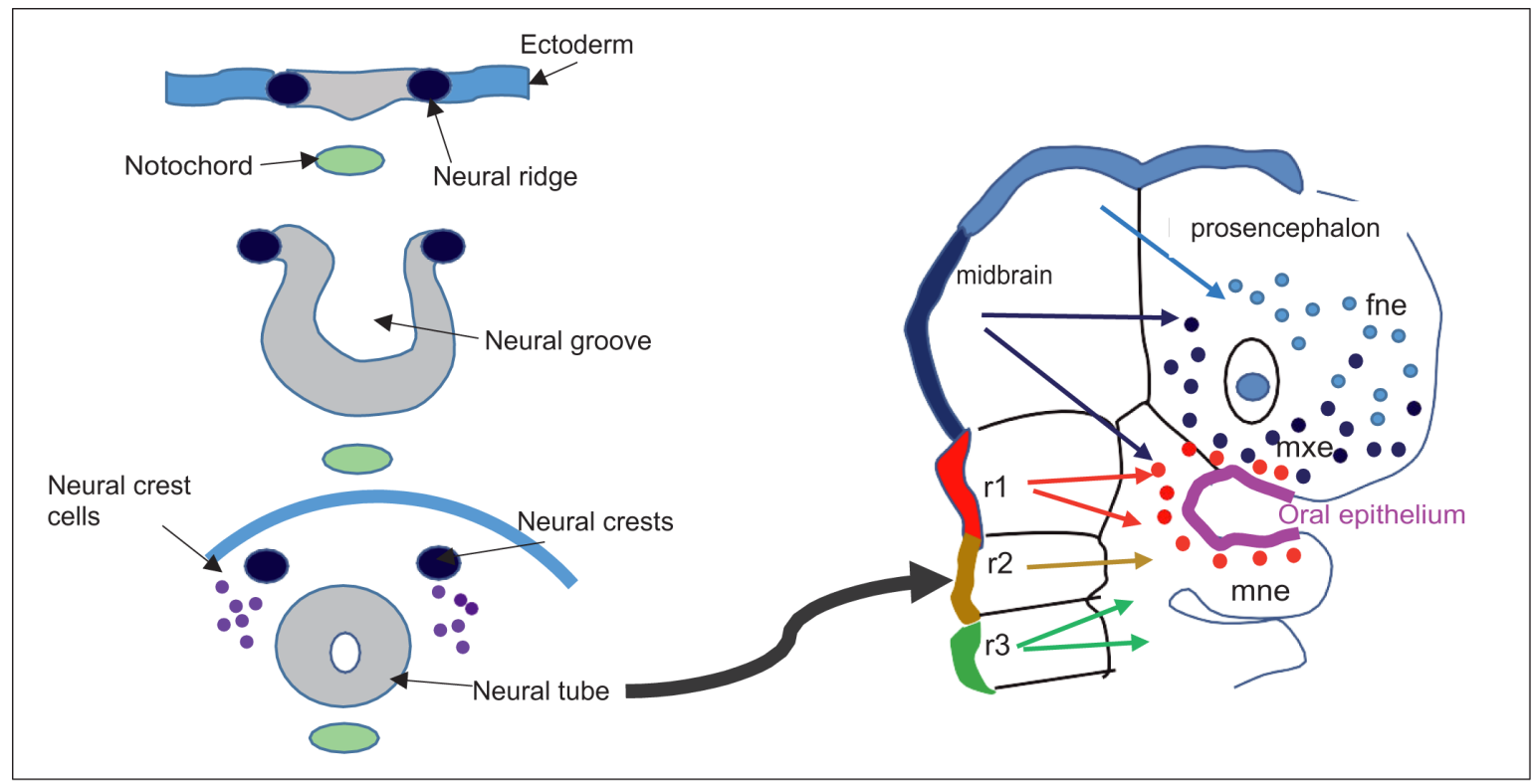

Figure $1 \mathrm{~A}$

Formation of the craniofacial skeleton. Left: formation of neural tube from neural ectoderm. Arrow shows migration of neuroectodermal cells originating in the dorsal aspect of the neural tube, to form facial structures via 5 branchial or pharyngeal arches. r1, r2, r3: rhombohedra; fne: fronto-nasal extension; mxe: maxillary extension; mne: mandibular extension.

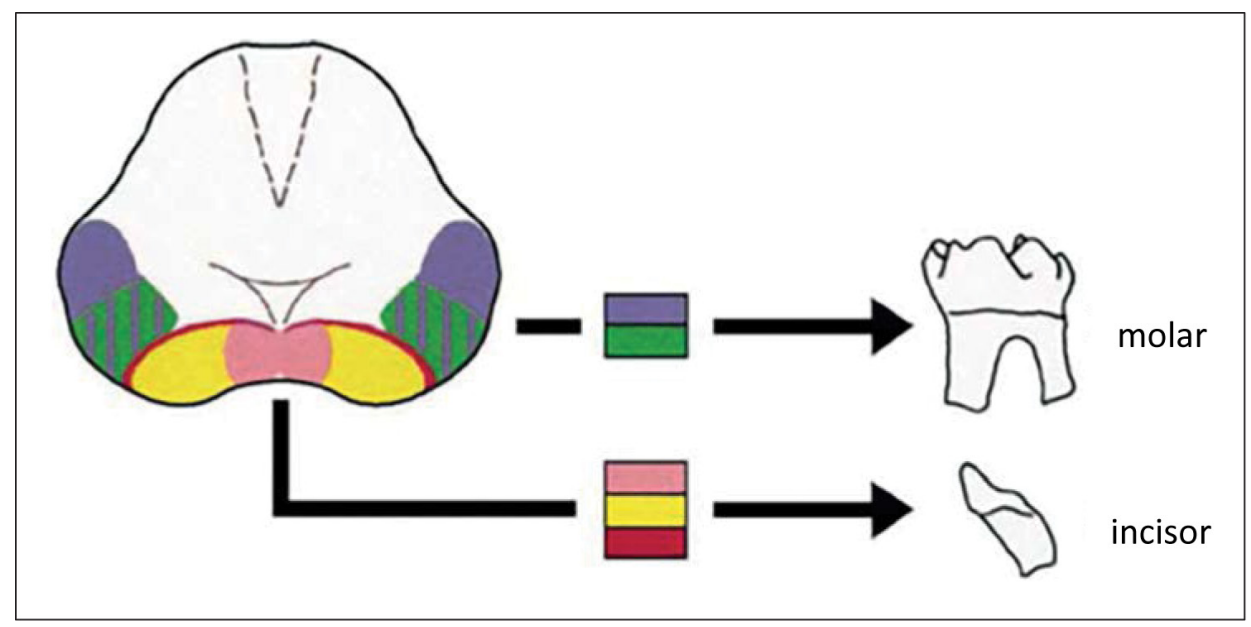

Figure $1 B$

Diagram of Sharpe's "dental homeocode", modified by Cobourne?. Colors represent specific genetic programs for each distal and proximal sector, underlying the formation of each dental unit. 

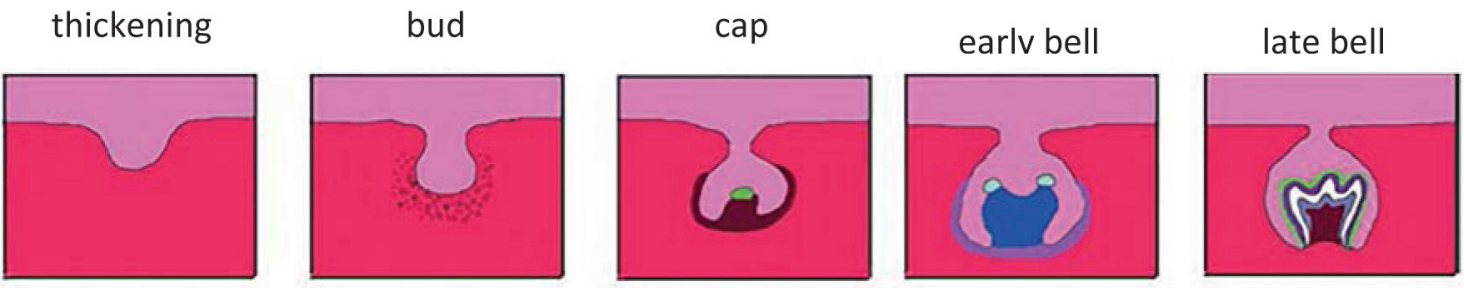

Figure $1 C$

Diagram of early odontogenesis from invagination of the odontogenic epithelium of the underlying ectomesenchyme, inducing several successive stages known as bud, cap and bell

structures are covered externally by ectoderm and internally by ectoderm in the case of the first arch and endoderm for the others. The branchial arches form 7 extensions (1 fronto-nasal, 2 nasal, 2 maxillary and 2 mandibular), each with specific molecular characteristics and epithelial interactions ${ }^{32}$. The maxillary and mandibular extensions derive from the $1^{\text {st }}$ branchial arch and their development requires interaction between epithelium, NCCs, mesoderm and pharyngeal endoderm. A molecular program, based on growth factors (BMP: Bone Morphogenetic Protein; WNT; FGF: Fibroblast Growth Factor, etc.) and numerous transcription factors (MSX1/2, PAX3/7, DLX3/5, GBX2, ZIC1, SNAIL, SOX-E, FOXD3), controls these interactions ${ }^{30}$.

Odontogenesis begins very early in embryonic development, with the establishment of the initial maxillary template. More precisely, a spatial combination of molecular signals determines the type and inter- and intramaxillary position of each dental-alveolar unit (fig. 1B). In the mid-1990s, Paul Sharpe called this a "dental homeocode" 39,7,36.

According to this homeocode, the maxillary proximal-distal and oralaboral axes are established by the
BMP (BMP4: Bone Morphogenetic Protein 4) and FGF (FGF8 and 9, Fibroblast Growth Factors 8 and 9) growth-factor family signaling pathways, expressing in the distal and proximal sectors, respectively? FGF8 and 9 induce expression of homeoproteins LHX6 and 7 (Limhomeobox Gene), DLX1 and 2 (Distal-Less Homeobox Gene) and BARX1 (Bar Class Homeobox Gene) and mesenchymal markers of the proximal oral region ${ }^{13,37}$. In contrast, FGF8 and 9 suppress expression of GSC (Goosecoid Gene), an aboral mesenchyme marker. Expression of BMP4 in the distal oral ectoderm induces expression of MSX1 and 2 (Muscle Segment Homeobox Gene) in the incisor region and limits expression of BARX1 ion the proximal part of the maxilla where the molars form. If BMP4 signaling is inhibited, by Noggin for example, BARX1 is expressed in the region of the future incisors, which undergo "homeotic" transformation into mo$\operatorname{lars} 43,40$.

DLX family members are more widely involved in maxillary morphogenesis ${ }^{8}$. DLX-mutant mice show several skeletal defects. Expression of homeoproteins DLX-1 and -2 is restricted to cells of the maxillary proximal ectomesenchyme, where 


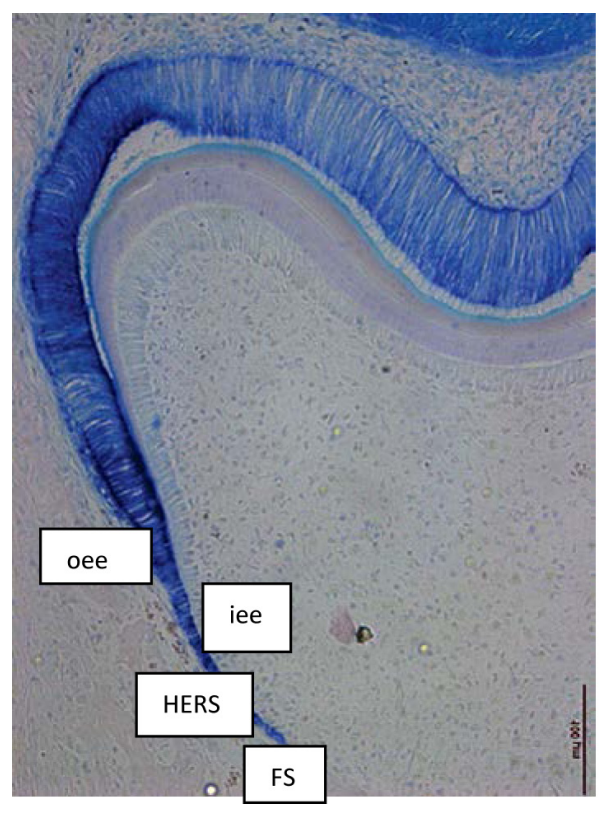

Figure 2A

Histologic cross-section of murine first molar, at

5 days. Formation of Hertwig's epithelial root sheath (HERS). oee: outer enamel epithelium; iee: inner enamel epithelium; FS: follicular sac

only molars develop. DLX-1 and -2 are targets for fibroblast growth factor (FGF) 8, and DLX-1 and -2 knockout mice show selective superior molar loss ${ }^{20,40}$. In the mandible, there is functional redundancy between DLX5 and DLX68. These DLX homeoproteins are necessary for BARX1 expression in the odontogenic mesenchyme ${ }^{43}$, which otherwise loses its mandibular odontogenic potential, becoming chondrogenic, as is the case for superior molars in DLX-1 -2 double-knockout mice ${ }^{37}$.

Following initiation (antenatal period), morphogenesis comprises a series of epithelial-mesenchymal interactions, morphologically consisting in invagination of the odontogenic epithelium of the underlying ectomesenchyme (developing from the cephalic neural crests), in successive stages known as bud, cap and bell (fig. 1C26).

In the cap stage (E14.5 in mice), two cellular layers form in the peripheral part of the dental epithelium: internal (IEE) and outer (OEE) enamel epithelium; The ectomesenchyme condenses adjacent to IEE to form the mesenchymal papilla and the cells of the follicular sac. Within the central IEE, the primary enamel knots begins to appear, in a signaling center expressing several transcription factors. At the bell stage (E16.5), the previous cellular developments increase. In the dental epithelium, four cellular layers can be distinguished: OEE, IEE, stellate reticulum (SR) and stratum intermedium (SI). Within the dental mesenchyme, two tissue regions can be distinguished: the mesenchymal papilla, facing the IEE, and the follicular sac, surrounding the system formed by the dental epithelium and the mesenchymal papilla Within the IEE, secondary enamel knots appear in the future cusp regions, underlying later morphogenesis ${ }^{18}$. They express and secrete the same factors as the primary knots, but are not involved in proliferation, rather controlling cell differentiation.

After the crown has been formed, root morphogenesis begins, with Hertwig's epithelial root sheath ${ }^{49}$, a double layer of epithelial cells which fuse at the extremities of the enamel organ once the crown is completely formed. On the classic theory of root formation, the Hertwig epithelial root sheath cells proliferate and migrate apically, separating the ecto-mesenchyme in two: radicular mesenchymal papilla, and follicle sac (fig. 2A). 


\section{FORMATION OF ALVEOLAR BONE AND DENTAL ERUPTION}

The alveolar bone develops in coordination with the tooth. More precisely, growth in tooth volume, of both crown and root, and relative dental germ displacement during growth involve peripheral alveolar bone modeling 29,17,22. Although dental growth has been shown not to depend on root formation ${ }^{4}$, the bone crypt still has to adapt to crown and root formation and bone modeling related to eruption $23,25,24$. This modeling, like the bone remodeling that has

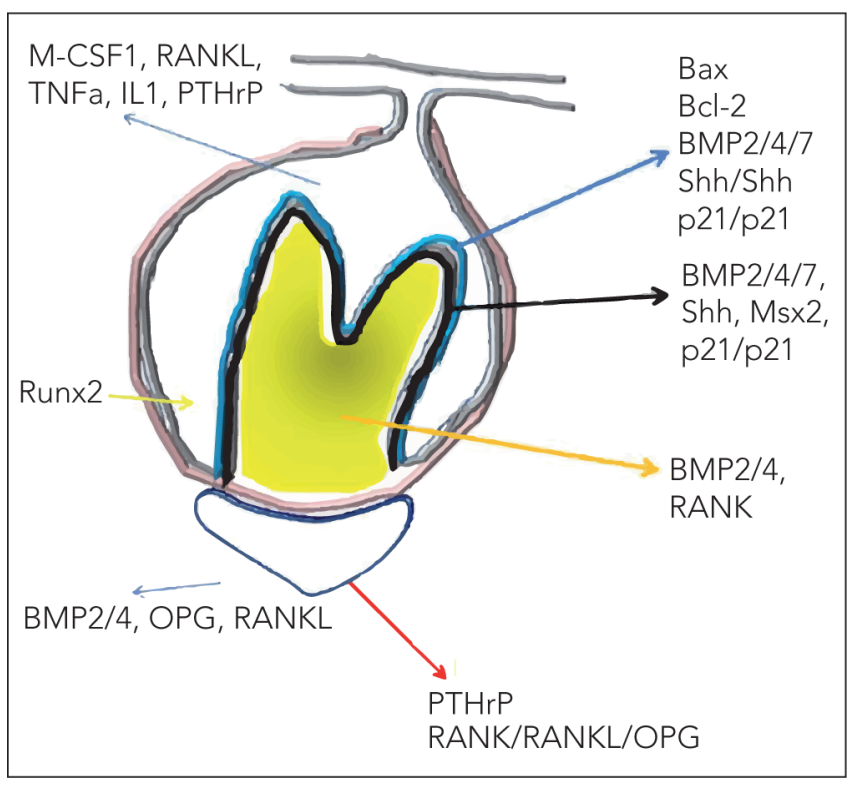

Figure 2B

Diagram of signaling pathways in coupling between dental epithelium cells, follicular sac and alveolar bone during alveolar bone modeling. M-CSF1: Macrophage Colony Stimulating Factor; RANKL: Receptor Activator of Nuclear factor Kappa-B Ligand; RANK: Receptor Activator of Nuclear factor Kappa-B; OPG: Osteoprotegerin; TNFa: Tumor Necrosis Factor alpha; PTHrP:

Parathyroid Hormone-related Protein; BMP: Bone Morphogenetic Protein; Shh: Sonic Hedgehog; Msx2: Muscle Segment Homeobox 2; p21: Cyclin-Dependent Kinase Inhibitor 1. been clearly described in the axial and appendicular skeleton, involves resorption and apposition, and the emergence of site specificity. The two processes are known to be coupled, and are founded on the recruitment and activation of highly specialized cells: respectively, osteoclasts and osteoblasts.

Dental eruption is the process by which the tooth emerges from the bone sac after resorption of the overlying alveolar bone and reduction of the oral epithelium. The mechanism underlying the eruption pathway seems to be highly complex, depending not on the pressure of the tooth on the surrounding bone, but on programmed and coordinated local bone resorption, independently of root formation ${ }^{41,4}$. Eruption involves coupling and uncoupling between tooth and bone, via signaling pathways between dental epithelial cells, follicular sac and alveolar bone (fig. 2B), some of which have been well described. They involve transcription factors, proto-oncogenes and growth factors ${ }^{44,47}$, and can be divided into two categories.

The first are those enabling timely recruitment, at the correct site, of effector cell precursors such as osteoclasts. The second are those inducing differentiation and modulating cell activation. In the first category, the main pathways initiating dental eruption are those triggering the arrival of mononuclear cells in the follicle. M-CSF and MCP-1 are the first two factors shown to be involved in mononuclear cell (osteoclast) recruitment in the dental follicle ${ }^{42}$. Interestingly, 


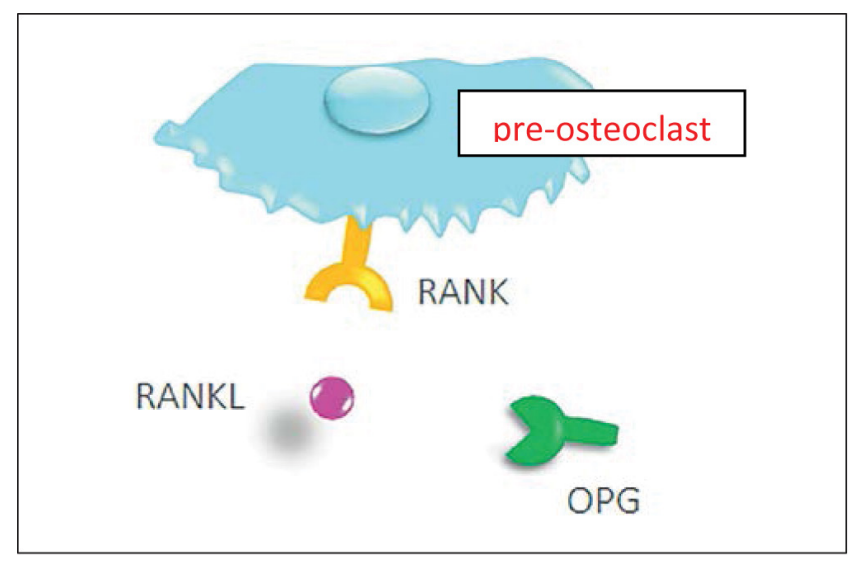

Figure $3 A$

Diagram of RANK/RANKL/OPG pathway. RANKL activates osteoclast differentiation by fixing to the RANK receptor on osteoclast precursor cells. Osteoprotegerin (OPG) totally inhibits osteoclast differentiation.

M-CSF is necessary for osteoclast formation from mononuclear precursors ${ }^{19}$, which are thus also part of the second category of pathways. Other molecules known to stimulate eruption are expressed in the follicle, such as interleukin 1 alpha and PTH-rP45, and have been shown to stimulate expression of M-CSF and MCP-1 ${ }^{31}$.

The main pathway in the second category is the RANKL/RANK pathway. It induces precursor fusion and osteoclast functional differentiation ${ }^{34}$.

RANKL, synthesized by stromal cells, activates osteoclast differentiation by fixing to the RANK receptor on the osteoclast precursor cell surface. Osteoprotegerin (OPG) totally inhibits osteoclast differentiation (fig. $3 \mathrm{~A})$. It is a soluble protein, structurally closer to the RANK protein, to which it can thus bind and block RANKL induction of osteoclast differentiation $^{41,43}$

Expression of RANKL and OPG is governed by several hormones and cytokines that control bone resorption by direct action on the osteoblasts and stromal cell secreting them, and include parathyroid hormone, vitamin D, TNF (Tumor Necrosis Factor) alpha, interleukin 1,6 and 11, M-CSF, prostaglandin E2 and EGF

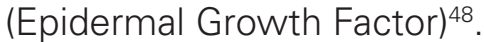

Most studies of the involvement of the RANKL/RANK/OPG triad confirmed its importance in alveolar bone modeling and remodeling and in maintaining periodontal ligament integrity ${ }^{5,15}$. They demonstrated that, under physiological conditions, RANKL and OPG are expressed in the follicle during eruption and in the

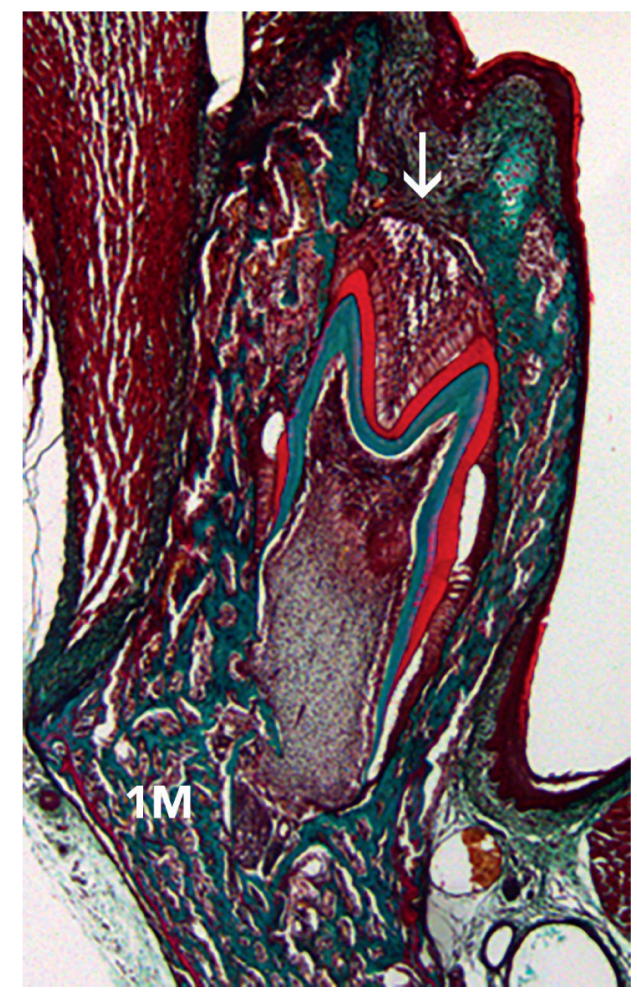

Figure $3 B$

Histologic cross-section of RANKL-knockout mouse molar at 8 days of life. Arrow shows non-formation of the eruption pathway, usually present at that age. 
adult alveolodental ligament during periodontal homeostasis. RANKL activation of osteoclastogenesis is important for the formation of the eruption pathway and alveolar bone adaptation to growth in tooth volume. Overexpression of RANK in pre-osteoclasts accelerates molar eruption in mice ${ }^{6}$ and, conversely, teeth fail to erupt in RANKL-knockout mice (fig. 3B ${ }^{12}$ ). In rats, Wise $e^{46,47,48}$ showed reduced OPG expression at day 3 of life to be associated, in the alveolar bone, with increased RANKL expression and osteoclast production. In-vitro studies clearly established that OPG expression is inhibited by M-CSF and PTH-rP, promoting RANKL signaling ${ }^{27}$. It was therefore suggested that expression of M-CSF and PTH-rP in the dental follicle and stellate reticulum respectively lowers expression of $\mathrm{OPG}^{22}$, and increases RANKL expression and function and thus osteoclast differentiation.

The importance of PTH-rP for eruption was demonstrated in vivo: in PTH-rP knockout mice, eruption is totally interrupted ${ }^{28,29}$. PTH-rP was also shown to increase RANKL expression and reduce OPG expression in periodontal ligament cells ${ }^{12}$, inducing not only tooth displacement during eruption but also deciduous tooth root resorption ${ }^{12}$. Mutation of the gene coding for the $\mathrm{PTH}-\mathrm{rP}$ receptor (PTHR1), reported in 3 unrelated families, was associated with primary failure of eruption (PFE) of the molars (Online Mendelian Inheritance in Man (OMIM) \# 125350).

PTHR1 knockout mice show a similar phenotype, with tooth retention in the alveolar bone ${ }^{14,38}$. Further analysis showed that loss of PTHR1 function did not directly impact osteoclast activity but disturbed epithelial-mesenchymal interaction, impacting the teeth although occurring earlier than eruption². Taken together, these findings show that dental and periodontal tissue signaling to the cells resorbing the bone is a key element in physiological dental eruption.

Root formation, like eruption, requires bone lodge modeling coordinated in space and time with root lengthening and the formation of insertion tissue: cementum and periodontal ligament.

Hertwig's epithelial root sheath plays an important role in root lengthening by tissue interaction with the pulpar mesenchyme and dental follicle. Sheath cells express epithelial molecules such as cytokeratins, Ecadherin and ameloblastin, and also mesenchymal molecules such as BSP, vimentin and $\mathrm{N}$-cadherin 1 10,11,33,50. The interaction mechanisms between sheath epithelial cells and mesenchymal cells and the signaling pathways involved are as yet unknown. Interactions between epithelium and dental mesenchyme have been widely studied in early development ${ }^{35}$, but few studies have focused on communication between dental epithelial root cells and bone cells during later development and root growth, most being conducted in osteopetrosis, where root lengthening is strongly disordered $^{9}$. Such root deformities are interpreted as dental lesions secondary to a mechanical problem of failed eruption pathway formation and alveolar bone pressure on the lengthening $\operatorname{root}^{16}$. 
Recent studies by Berdal's team (Oral and Molecular Physiology Laboratory, UMRS 1138) showed that bone resorption disorder (deficient or excessive) impacts dental eruption and root morphogenesis (fig. 3B $)^{5}$. More precisely, resorption deficit (e.g., RANKL or RANKL-knockout mice) induces delayed eruption and shorter roots of greater diameter, whereas over-resorption (mice overexpressing RANK in pre-osteoclasts) greatly accelerates eruption and root formation, leading to roots of smaller diameter ${ }^{6}$. The implicated mechanisms are not yet fully understood, but it is clear that there is signaling from bone cells (osteoclasts and osteoblasts) toward dental and periodontal cells during dental lengthening and eruption. One explanation for inclusion specific to one type of tooth ( $2^{\text {nd }}$ molars or $2^{\text {nd }}$ premolars) is transiently impaired signaling between dental and bone cells during the time window of the specific tooth lengthening. Studies in mice, transiently blocking osteoclast activity at various time points, are underway, using a RANKL-blocking antibody; initial results suggest that very early blocking (days 1-5) inhibits eruption and root lengthening definitively in $1^{\text {st }}$ molars but transiently in $2^{\text {nd }}$ and $3^{\text {rd }}$ molars ${ }^{21}$. Later blocking (days 4-7) should induce maximal inhibition of $2^{\text {nd }}$ molars, with $1^{\text {st }}$ and $3^{\text {rd }}$ molars only transiently affected.

\section{Conflict of interest}

The authors declare no conflict of interest.

\section{REFERENCES}

1. Akimoto T, Fujiwara N, Kagiya T, Otsu K, Ishizeki K, Harada H. Establishment of Hertwig's epithelial root sheath cell line from cells involved in epithelial-mesenchymal transition. Biochem Biophys Res Commun 2011;404(1):308-12.

2. Boabaid F, Berry JE, Koh AJ, Somerman MJ, McCcauley LK. The role of parathyroid hormone-related protein in the regulation of osteoclastogenesis by cementoblasts. J Periodontol 2004;75(9):1247-54.

3. Bronner ME, LaBonne C. Preface: the neural crest-from stem cell formation to migration and differentiation. Dev Biol 2012;366(1):1.

4. Cahill, DR, Marks SC. Tooth eruption: evidence of the central role of the dental follicle. J Oral Pathol 1980;9:189-200.

5. Castaneda B, et al. Impact de l'inhibition de RANKL dans la formation radiculaire des molaires murines. Soumis.

6. Castaneda $\mathrm{B}$, et al. Bone resorption control of tooth eruption and root morphogenesis: Involvement of the receptor activator of NF-KB (RANK). J Cell Physiol 2011;226(1):74-85.

7. Cobourne MT, Mitsiadis T. Neural crest cells and patterning of the mammalian dentition. J Exp Zool B Mol Dev Evol 2006;306:251-60.

8. Depew MJ, Simpson C, Morasso M, Rubenstein JL. Reassessing the Dlx code: the genetic regulation of branchial arch skeletal pattern and development. J Anat 2005;207(5):501-61.

9. Everts V, de Vries TJ, Helfrich MH. Osteoclast heterogeneity: lessons from osteopetrosis and inflammatory conditions. Biochim Biophys Acta 2009;1792(8):757-65. 
10. Fong CD, Hammarström L. Expression of amelin and amelogenin in epithelial root sheath remnants of fully formed rat molars. Oral Surg Oral Med Oral Pathol Oral Radiol Endod 2000;90(2):218-23.

11. Fong CD, Hammarström L, Lundmark C, Wurtz T, Slaby I. Expression patterns of RNAs for amelin and amelogenin in developing rat molars and incisors. Adv Dent Res 1996;10(2):195-200.

12. Fukushima H, Jimi E, Kajiya H, Motokawa W, Okabe K. Parathyroid-hormone-related protein induces expression of receptor activator of NF-\{kappa\}B ligand in human periodontal ligament cells via a cAMP/ protein kinase A-independent pathway. J Dent Res 2005;84(4):329-34.

13. Grigoriou M, Tucker AS, Sharpe PT, Pachnis V. Expression and regulation of Lhx6 and $\mathrm{LhX7}$, a novel subfamily of LIM homeodomain encoding genes, suggest a role in mammalian head development. Development 1998;125(11):2063-2074.

14. Harokopakis-Hajishengallis E. Physiologic root resorption in primary teeth: molecular and histological events. J Oral Sci 2007;49(1):1-12.

15. HasegawaT, et al. Expression of receptor activator of NF-kappa B ligand and osteoprotegerin in culture of human periodontal ligament cells. J Periodontal Res 2002;37(6):405411.

16. Heilfrich $\mathrm{MH}$. Osteoclast diseases and dental abnormalities. Arch Oral Biol 2005;50(2):115-122.

17. Heinrich J, Bsoul S, Terezhalmy G, Woodruff K, Abboud SL. CSF-1, RANKL, OPG regulate osteoclastogenesis during murine tooth eruption. Arch Oral Biol 2005;50(10):897908.

18. Jernvall J, Thesleff I. Reiterative signaling and patterning during mammalian tooth morphogenesis. Mech Dev 2000;92(1):19-29.

19. Kim JH, Kim N. Regulation of NFATc1 in Osteoclast Differentiation. J Bone Metab 2014;21(4):233-41.

20. Lezot $F$, et al. Physiological implications of DLX homeoproteins in enamel formation. $J$ Cell Physiol 2008;216(3):688-97.

21. Lézot $F$, et al. Skeletal consequences of RANKL-blocking antibody (IK22-5) injections during growth: Mouse strain disparities and synergic effect with zoledronic acid. Bone 2015;73:51-9.

22. Liu D, Yao S, Pan F, Wise GE. Chronology and regulation of gene expression of RANKL in the rat dental follicle. Eur J Oral Sci 2005;113(5):404-409.

23. Marks SC Jr, Cahill DR. Ultrastructure of alveolar bone during tooth eruption in the dog. Am J Anat 1986;177(3):427-38.

24. Marks SC Jr, Schroeder HE. Tooth eruption: theories and facts. Anat Rec 1996;245(2):37493, Review.

25. Marks SC Jr, Cahill DR. Regional control by the dental follicle of alterations in alveolar bone metabolism during tooth eruption. J Oral Pathol 1987;16(4):164-9.

26. Mitsiadis TA, Graf D. Cell fate determination during tooth development and regeneration. Birth Defects Res (part C) 2009;87(3):199-211.

27. Nakchbandi IA, Weir EE, Insogna KL, Philbrick WM, Broadus AE. Parathyroid hormonerelated protein induces spontaneous osteoclast formation via paracrine cascade. Proc Natl Acad Sci USA 2000;97(13):7296-7300.

28. Ohazama A, Courtney JM, Sharpe PT. OPG, RANK, RANKL in tooth development coordination of odontogenesis and osteogenesis. J Dent 2004;83(3):241-244.

29. Philbrick WM, Dreyer BE, Nakchbandi IA, Karaplis AC. Parathyroid hormone-related protein is required for tooth eruption. Proc Natl Acad Sci USA 1998;95(20):11846-51. 
30. Prasad MS, Sauka-Spengler T, LaBonne C. Induction of the neural crest state: control of stem cell attributes by gene regulatory, post-transcriptional and epigenetic interactions. Dev Biol 2012;366(1):10-21.

31. Que BG, Wise GE. Tooth eruption molecules enhance MCP-1 gene expression in the dental follicle of the rat. Dev Dy 1998;212(3):346-351.

32. Radisky DC, LaBarge MA. Epithelial-mesenchymal transition and stem cell phenotype. Stem Cell 2008;2(6):511-2.

33. Sonoyama W, Seo BM, Yamaza T, Shi S. Human Hertwig's epithelial root sheath cells play crucial roles in cementum formation. J Dent Res 2007;86(7):594-9.

34. Suzuki T, Suda N, Ohyama K. Osteoclastogenesis during mouse tooth germ development is mediated by receptor activator of NFkappa-B ligand (RANKL). J Bone Miner Metab 2004;22(3):185-91.

35. Thesleff, I. Epithelial-mesenchymal signalling regulat- ing tooth morphogenesis. J Cell Sci 2003;116:1647-1648.

36. Thomas BL, Tucker AS, Ferguson C, Qiu M, Rubenstein JL, Sharpe PT. Molecular control of odontogenic patterning: positional dependent initiation and morphogenesis. Eur J Oral Sci 1998;106 Suppl 1:44-7.

37. Thomas $B L$, et al. Role of $D \mid x-1$ and $D \mid x-2$ genes in patterning of the murine dentition. Development 1997;124(23):4811-8.

38. Tsutsui TW, Riminucci M, Holmbeck K, Bianco P, Robey PG. Development of craniofacial structures in transgenic mice with constitutively active PTH/ PTHrP receptor. Bone 2008;42(2):321-31.

39. Tucker AS, Sharpe PT. Molecular genetics of tooth morphogenetics and patterning: the right shape in the right place. J Dent Res 1999;78(4):826-834.

40. Tucker AS, Matthews KL, Sharpe PT. Transformation of tooth type induced by inhibition of BMP signaling. Science 1998;282(5391):1136-8.

41. Wada N, et al. Periodontal ligament cells secrete the factor that inhibits osteoclastic differentiation and function: the factor is psteoprotegerin/osteoclastogenesis inhibitory factor. J Periodontal Res 2001;36(1):56-63.

42. Wang JM, Chen ZG, Colotta F, Mantovani V. Role of GM-CSF in phagocyte recruitment and regulation of c-fosprotooncogene expression. Behring Institute Mitteilungen 1988;83:270-3.

43. Wilson J, Tucker AS. Fgf and Bmp signals repress the expression of Barx1 in the mandibular mesenchyme and control the position of the developing jaw joint. Dev Biol 2004;266(1):138-150.

44. Wise GE, King GJ. Mechanisms of tooth eruption and orthodontic tooth movement. J Dent Res 2008;87(5):414-434.

45. Wise GE, Lin F. Regulation and localization of colony-stimulating factor-1 mRNA in cultured rat dental follicle cells. Arch Oral Biol 1994;39(7):621-627.

46. Wise GE, Ren Y, Yao S. Regulation of osteoprotegerin gene expression in dental follicle cells. J Dent Res 2003;82(4):298-302.

47. Wise GE, Yao S, Zhang Q, Ren Y. Inhibition of osteoclastogenesis by the secretion of osteoprotegerin in vitro by rat dental follicle cells and its implications for tooth eruption. Arch Oral Biol 2002;47(3):247-254.

48. Wise GE, Yao S. Regional differences of expression of bone morphogenetic protein-2 and RANKL in the rat dental follicle. Eur J Oral Sci 2006;114(6):512-516.

49. Yamamoto H, Cho SW, Kim EJ, Kim JY, Fujiwara N, Jung HS. Developmental properties of the Hertwig's epithelial root sheath in mice. J Dent Res 2004;83(9):688-92.

50. Zeichner-David M, et al. Role of Hertwig's epithelial root sheath cells in tooth root development. Dev Dyn 2003;228(4):651-63. 